\title{
Making Nature Explicit in Children's Drawings of Wellbeing and Happy Spaces
}

\author{
Zoe Moula $^{1}$ (iD $\cdot$ Nicola Walshe ${ }^{1} \cdot$ Elsa Lee $^{1}$
}

Accepted: 11 February 2021/Published online: 24 March 2021

(C) The Author(s), under exclusive licence to Springer Nature B.V. 2021

\begin{abstract}
Previous research on children's wellbeing indicators has focused extensively on adults', rather than children's perspectives, despite there being a broad consensus that children's conceptualisations differ significantly from adults'. In response, this study aimed to explore what constitutes children's wellbeing through their drawings and discussions. Ninety-one seven and eight-year old children from two primary schools in areas of relatively high deprivation in eastern England participated in this study. We identified indicators of wellbeing that were made explicit in children's drawings, such as the need for safety, happiness and positive relationships, but also indicators that remained rather implicit, such as the environment and nature. The drawings in particular illustrated that children's perceptions of wellbeing were subject to the affordances of their favourite spaces for emotional, mental physical and material wellbeing. Access to nature and outdoor spaces was interconnected with all these affordances. We analysed these findings through the theoretical lenses of positive psychology, self-actualisation, social mentality and the human-nature relationship. We argue that making nature explicit, and restoring the interconnectedness between the arts and nature in the current literature, should be a key priority for future research and practice on children's wellbeing indicators.
\end{abstract}

Keywords Child wellbeing indicators $\cdot$ Child voice $\cdot$ Nature connectedness $\cdot$ Art-based research $\cdot$ Environmental sustainability education

\section{Introduction}

Over the past two decades, research on child wellbeing has expanded to become a significant international focus; this has arisen as a result of increased attention on

Zoe Moula

zoi.moula@aru.ac.uk

Faculty of Health, Education, Medicine \& Social Care, Anglia Ruskin University, Cambridge, UK 
children's rights, and the sociology of childhood and social constructionism as frameworks for undertaking research 'with' children (Fattore et al., 2019). Evidence also suggests that children's wellbeing is a crucial indicator of educational attainment, fulfilment, and productivity (Land \& Michalos, 2018), and has clear links with wellbeing in adolescence and adulthood (Kamerman et al., 2003). For these reasons, as well as being important for children's daily experience of the world, researching children's wellbeing can be considered as 'investment in the future' (Thomas et al., 2016). This research which we discuss in the next section draws from the disciplines of child psychology and the sociology of childhood, as well as from education; it is, thereby, represented by different disciplinary frameworks. However, there is a need for integration across these different disciplines to ensure a more holistic understanding of the influences on children's wellbeing.

For example, the burgeoning evidence that physical environments have a strong impact on health and wellbeing (Barnes, 2006; Edwards \& Bromfield, 2009; Pebley \& Sastry, 2004) does not feature significantly in the general literature on children's wellbeing. Connectedness with nature has been found to be associated with aspects of wellbeing, such as life satisfaction (Mayer \& Frantz, 2004), vitality (Cervinka et al., 2011) and happiness (Capaldi et al., 2014). Particularly in childhood, access to nature and green spaces has been linked with lower life stress (Wells \& Evans, 2003) and improved emotional regulation, which can prevent adulthood depression (Snell et al., 2016). There is also substantial evidence demonstrating that opportunities for creativity and engagement with the arts have a significant impact on health and wellbeing (Daykin, 2019; Clift \& Stickley, 2017; Moula, 2020; Moula et al., 2020). A recent scoping review synthesising outcomes from 3000 global studies (Fancourt \& Finn, 2019) found that arts play a major role in the prevention of ill health, promotion of health, and health management across the lifespan. However, what has received scant attention in the literature so far is the interconnectedness between the two: the arts and nature; this demonstrates the need for integration we have identified above.

We have begun to explore the role of the arts and nature on children's wellbeing through a number of recent studies and publications. In the most recent article investigating artist pedagogue perceptions of supporting children's wellbeing through art in nature (Walshe et al., 2020b), our review of the literature suggested that, although there are proven links separately between nature and wellbeing, and art and wellbeing, there are very few examples of the amalgamation of both. In these few cases, the benefits for children's wellbeing were highlighted. For example, children's engagement in creative and imaginative play in woodland and outdoor spaces was found to have a restorative effect on their physical and emotional wellbeing, with a particularly strong impact on the development of autonomy, empathy and risk-taking (Milligan \& Bingley, 2007; Rudkowski, 2014). In an ethnographic case study, we explored in particular how arts-based practice in nature is perceived by artists as being transformative for children's lives. The benefits artists identified included improved imagination, freedom of expression, ownership over aspects of life, and concern for other people as well as for the environment. What is missing from the existing evidence, however, are the voices of children. Our current study, Eco-Capabilities, aims to address this, creating a space to bring art and nature together, and contributing to a more holistic understanding of what is important for children's wellbeing. 
The following section focuses on the current debates and literature review on children's wellbeing, followed by the aims and scope of the present study.

\subsection{Understanding children's Wellbeing}

Wellbeing has been expressed through a number of indicators, such as health, safety, happiness, healthy relationships and opportunities for learning, as well as wealth and material resources (Diener \& Seligman, 2004; Maccagnan et al., 2019; Stiglitz et al., 2009). It has also been used as a broader concept to describe people's quality of life and life satisfaction, terms that have been used interchangeably in the evidence-base (Petermans \& Cain, 2019; Selwyn \& Wood, 2015). Because of the complexity of this dynamic and multifactorial term, the incorporation of physical, psychological, emotional and social aspects into a single notion has been challenging (Moore \& Oberklaid, 2014). There is currently no consensus on how wellbeing should be defined (Misra, 2018; Forgeard et al., 2011; Gillett-Swan \& Sargeant, 2014), as the existing definitions are both variable and can appear to be conceptually confused (Streuli et al., 2009). For example, most definitions adopt a pathogenic approach (Amerijckx \& Humblet, 2013), whereas the concept of wellbeing has emerged from positive psychology and aims to uncover factors that maximise health promotion, rather than to 'pathodologise' health (Seligman \& Csikszentmihalyi, 2000).

The definition of wellbeing becomes even more complex when it refers to children and young people (Moore \& Oberklaid, 2014). At the earlier stages of research, the assessment of children's wellbeing was made by adults (i.e. parents, teachers) (Fane et al., 2020). However, research exploring children's perceptions has evolved in recent years with increasing acknowledgment that children have a substantial insight into their own wellbeing (Andresen et al., 2019). There is a growing body of knowledge highlighting the importance of examining young children's perceptions about their lives, demonstrating that these perceptions can be both accurate and reliable (Andresen et al., 2017; Ben-Arieh \& Kosher, 2018; Sofer \& Ben-Arieh, 2014). The first worldwide research project on children's subjective wellbeing - 'Children's Worlds: The International Survey of Children's Well-Being project' - has now collected data from more than 17,000 children. The findings suggest that children as young as eight are aware of their own needs and, therefore, any effort to improve their wellbeing needs to include their voice (Rees et al., 2016). As Devlin and Appleby (2010) suggest, when children are properly asked, they can be the best source of information for their own assessment of health and wellbeing. It is worth noting here that research in environmental education about how children's environments affect their wellbeing has long foregrounded the need for children's voice (i.e. Barratt Hacking et al., 2007). As such, this move in psychology towards capturing children's voices as to what constitutes wellbeing, and how they perceive their own wellbeing (Andresen \& Fegter, 2011; Fane et al., 2020; Fattore et al., 2017; Laurens et al., 2017; Redmond et al., 2016) is long overdue.

Findings from studies that have investigated children's perspectives suggest that emerging indicators of wellbeing fall under the following domains: relationships with family and friends; school and local environment (broadly conceived but mostly 
focused on social environment); physical, emotional and material wellbeing; and selfperception (Fane et al., 2020; Fattore et al., 2009; Coverdale \& Long, 2015; Steckermeier, 2018; Andresen \& Fegter, 2011; Children's society, 2012). However, many of these have been overlooked in the existing policy and social indicator frameworks (Fane et al., 2020). What also appears to be missing is integration with the importance of nature and the arts, as we began to argue above. Former studies have commonly used open questions within interviews and focus groups (Fane et al., 2020; Fattore et al., 2009; Andresen \& Fegter, 2011); the absence of analysis relating to nature and the arts, therefore, suggests that these aspects of wellbeing might not be commonly articulated by children. In this study, we are keen to understand why this might be the case, and to use a wider range of methods to explore whether children communicate different things verbally and non-verbally.

\subsection{Nature Connections}

Whilst understanding the potential determinants of children's wellbeing is crucial, it is equally important to explore the factors that might act as barriers or burdens to children's wellbeing. With specific reference to the environment, there is a growing body of research which explores how children's wellbeing is adversely affected by the access they have to natural, outdoor spaces (or lack thereof); in particular, there is significant evidence that young people living in areas of high socio-economic deprivation are at the greatest risk in this regard. For example, Lee and Maheswaran (2010) found that wealth determines access to nature, while Marmot (2013) noted that children living in areas of high deprivation are nine times less likely to have access to green spaces and outdoor places to play. Inner city and poor populations were also found to be less likely to participate in outdoor recreation activities. Conversely, living in areas with access to green spaces has been shown to reduce income-related health inequalities, counteracting the effect of deprivation (Mitchell \& Popham, 2008). A research agenda mapped out by Jordan and Chawla (2019) regarding what they term 'Nature Based Learning' includes the need to consider such issues from the point of view of children's wellbeing. What is striking is that whilst areas of environmental psychology research do address these problems, the more traditional psychological research into children's wellbeing does not include access to nature and engagement with the arts. Quite why this is the case is unclear and it is a potential gap in the literature that our current study seeks to address.

\subsection{Study Aims and Scope}

Despite the benefits from the access to nature and outdoor spaces illustrated above, research suggests that large sections of the population spend little or no time outdoors, thereby remaining excluded from its suggested benefits for their health and wellbeing (Boyd et al., 2018). In response to the United Nations Sustainable Development Goal 3 (Ensure healthy lives and promote wellbeing for all at all ages) (WHO, 2015), governments and policy makers are currently focusing on the implementation of policies that may help to increase engagement with nature (Richardson \& McEwan, 2018; Natural England, 2019) and improve the human-nature relationship (Brymer 
et al., 2019). This is precisely the purpose of our current study, which is the first stage of the larger Eco-Capabilities research project. The overarching aim of Eco-Capabilities is to explore how the wellbeing of children living in areas of high deprivation can be supported through working with artists in nature and outdoor places. Drawing on Sen's capabilities approach (Sen, 2005), it asks children to define what is important for living a good life through environmental sustainability, social justice and future economic wellbeing (what we term as eco-capabilities). This wider project involves the engagement of artists with children in natural outdoor spaces for eight weeks; in this report, children's pre-intervention views on wellbeing will be presented and discussed.

The primary source of information was children's drawings which offered children the opportunity to express themselves in ways that go beyond verbal language and help them to communicate ideas that are not easily connected to words (Jones, 2005). This was particularly important considering that children aged seven to eight may have limited vocabulary and verbal skills to describe such complex concepts. To our knowledge, this is the first study to explore children's perceptions of wellbeing using drawings as a primary, rather than a complementary, methodological tool. The overarching research question for the Eco-Capabilities project is:

How does working with artists in nature influence children's wellbeing?

This current paper focuses on children's initial perceptions of wellbeing through their drawings, before the artist interventions in nature which were paused as a result of school closure during Covid-19.

\section{Methodology}

\subsection{Participants}

Four classes in Year 3 (ages seven and eight) from two primary schools in eastern England participated in this project; a total of 91 children. Both schools were located in areas with an IDACI (Income Deprivation Affecting Children Index - which measures the proportion of all children aged 0 to 15 living in income deprived families) of fourth quintile. Approximately 33\% of children in both schools have registered for Free School Meals (the National Average in 2018 was 13.6\%). In the first school approximately $30 \%$ of children have Special Educational Needs (SEN), and $28 \%$ have English as an Additional Language (EAL). In the second school, approximately $9 \%$ of children were identified as having a SEN and 39\% EAL. In 2018, the National Average in primary schools for SEN was $14.9 \%$ and for EAL $21.1 \%$. In this way, the research deliberately focused on children living in areas of high deprivation.

\subsection{Methods of Data Collection}

Participatory and arts-based research methodologies were the primary approaches adopted in this study (McNiff, 2009). The value of participatory and arts-based methods has been widely recognised for the potential to stimulate visual, rather than linguistic thinking (Cochran et al., 2008), thereby allowing children the space and time 
to uncover thoughts or experiences that they might struggle to verbalise (Culshaw, 2019). This is particularly important for young children at school in order not to feel concerned about whether their words or sentences follow certain grammatical rules (Cochran et al., 2008). In cases when words are inadequate to describe feelings and thoughts (Frosh, 2002; Leitch, 2006), the arts may become an alternative way of representing children's experiences, or to allow children to access words through different routes (Culshaw, 2019). In addition, arts-based methods offer children the opportunity to slow down and enjoy the process of meaning-making (Roberts and Woods, 2018). Such methods might also provide children with cathartic opportunities, when they become aware that their experiences and thoughts are being acknowledged and heard (Mannay et al., 2017). Thus, children's competencies could be promoted by allowing their voices to come through powerfully, and by challenging their disempowered social position (Kaushanskaya et al., 2017).

We explored children's perspectives on their wellbeing and 'happy places' through two main activities: the first asked children to draw their happy place, while the second comprised small group discussion around the concept of wellbeing. Within the first activity, children were initially invited to close their eyes, and imagine a place where they feel happy; either a real place they have visited in the past or an imaginary place. They were encouraged to use their senses and imagine how it feels, looks, sounds, or smells to be there; examples were avoided to ensure that children were not influenced by researchers' ideas. Children were then asked to open their eyes and draw this place as they imagined it; they were frequently reminded that there were no right or wrong answers, and that they should not be concerned about handwriting or spelling should they decide to use words. Children were also invited to draw five things that are important to them and they would definitely want in their happy and favourite place, as well as five things that they would rather keep away from it. This activity was completed by children individually so that they could focus on their own thoughts and experiences.

The second activity aimed to explore how wellbeing is perceived by children, what it means to them, and what they consider important for their wellbeing. Children were asked to consider these questions in groups of four to five to facilitate peer support when discussing such a complex and abstract concept. A subsequent whole-class discussion offered children the opportunity to share thoughts and ideas more widely.

Two researchers, two teachers and two artists were present in each class; teachers and artists had been trained as co-researchers for the project. The role of the adults was to facilitate the conversation where necessary, rather than to direct the children to certain ideas or responses. For example, when some groups were struggling to think what might be important for their wellbeing, the adults supported them by asking prompting questions, or by rephrasing questions. To reduce the potential power imbalance, the adults did the same activities as the children; they drew their own happy and favourite places. Advanced drawing skills and techniques were avoided in an effort to help children focus on their own thoughts rather than on their artistic skills.

\subsection{Methods of Data Analysis}

Thematic analysis was performed both on verbal and visual data (Braun \& Clarke, 2008); this method helps to construct meaning through the process of data 
familiarisation, coding, theme development and revision. Through the initial open process, coding was fluid and flexible so that codes could evolve and change. The reflexive, thematic analysis allowed for reflecting on how the researchers were conceptualizing the data, and how this conceptualisation was evolving, growing, or deepening alongside increased understanding of the data (Braun \& Clarke, 2008). The process of data analysis was undertaken by three researchers individually, and then collectively to explicate the emerging themes. This iterative process of repeated discussions aimed to ensure that our personal bias, sensitivities, allegiances and situated knowledge did not affect the direction of the findings, thus increasing the validity of the study (Denzin \& Lincoln, 2005).

\subsection{Ethical Considerations}

This project followed ethical guidelines in accordance with the Medical Research Council (MRC, 2012) and BERA (2018), and was awarded ethical approval by the Anglia Ruskin University Ethics Committee in February 2020. In order for children and parents or gatekeepers to be fully informed prior to their decision to participate, participant information sheets and consent forms detailed: the purpose and intentions of this study; foreseeable risks and benefits; information regarding anonymity, confidentiality, data protection and storage; and the right to withdraw at any stage without this choice affecting children's care. It was stressed anonymity of organisational identity could not be guaranteed because of the public nature of some of the activities, such as the art exhibitions. In addition, it was made clear that all children would have the opportunity to participate in the activities, even if they declined to participate in the research project; in this case, no data would be recorded or reported from these children. This process of gaining consent aimed to help children gain agency over their decision as to whether to participate, knowing that the research element would not deprive them of the opportunity to join in the activities.

We carefully crafted a set of open-ended instructions and prompts for the drawing activity to ensure both that we did not influence children's responses by overexemplification (Talmy, 2010), and to maintain a focus on positive mental wellbeing. Although we actively avoided triggering any deeper, negative emotional experiences, we were aware that exploring the idea of wellbeing might uncover personal and sensitive issues for some children, particularly within the context of the schools within which we were working. As such, a distress protocol and risk assessment was in place and any concerns were raised with the child protection officer or the safeguarding lead as per the schools' policies.

It is also important to highlight the context underpinning the current study. The data collection took place at the beginning of Covid-19 outbreak in March 2020, one week before the lockdown measures were implemented in the UK. This may have affected children's perceptions of their wellbeing, as well as their perceptions of their happy places.

\section{Results}

This section focuses on the themes that were identified from children's drawings and subsequent group discussions around wellbeing. In the description, the number of 
counts of each theme and sub-theme refers to the number of times that the items appeared in children's drawings and verbal expressions, while all the quotations mentioned come from children's verbal expressions.

The Venn diagram below illustrates the main themes and their interconnectedness. Children's perceptions of wellbeing can be categorized into three broad themes: i) emotional and mental wellbeing; ii) physical wellbeing; and iii) material wellbeing. Two further themes emerged: iv) the appreciation of and access to nature and outdoor spaces, and v) opportunities for learning, growth and leisure. These were seen as overarching or underpinning themes which cross-cut the first three; the nature of the relationship between these five themes will be explored further below.

\subsection{Emotional and mental wellbeing}

Children most commonly drew and talked about their emotional and mental wellbeing; within this category, five subthemes were identified. The most common was having family and friends as source of support $(n=41)$, and having pets as friends $(n=52)$ (Image 1). In children's words, it is crucial "to have someone in your house to love you and care about how you feel", "someone to talk to", and "someone to play with us". Some children mentioned the importance of knowing that these sources of support will continue even when they get older, for example: "having someone to take care of us when we are older and when we are sick". Furthermore, children acknowledged that all relationships face challenging times, yet it is crucial to know that these challenges will not affect their sense of security and safety; one child said "wellbeing is when you have troubles with your family but they are never seeing that", while another: "to be happy enough with your family". These phrases might suggest that children do not expect family and friends to always make them happy, but "to be always there when you need them". The last phrase, in particular, is linked to the second most emerging subtheme, the sense of safety in the environment $(n=31)$ and with people around you $(n=17)$. Most children did not elaborate further through examples, but they used synonyms, such as 'comfort', 'security', or 'shelter' on their drawings. Giving and receiving love and happiness was also important $(n=26)$ as children said that wellbeing is to have people that "make you smile and laugh", "to give you kisses, hugs and cuddles", but also "to make sure that people around you are happy too". This reflects previous studies which asked children about their wellbeing and which also found that a sense of safety and security was among the most important indicators of wellbeing (Fane et al., 2020; Fattore et al., 2009; Coverdale \& Long, 2015).

Another significant subtheme was that of imagination and play $(n=23)$. An unexpected observation was that several children acknowledged the importance of imagination not only for pleasure and fun, but also as a manner of improving our society. According to their dialogue: "wellbeing is to have the imagination to invent things" - "yes, things that help everyone to stay safe!". Having opportunities to expand the imagination was also articulated as being important: "wellbeing is making things that help you to imagine", and "making things that will help you get even better with your imagination". Examples from children's drawings included dragons, Pokémon, pixies, diplodocus, flying frogs, gingerflies, marshmallow chairs, and candy birds (Image 2). 


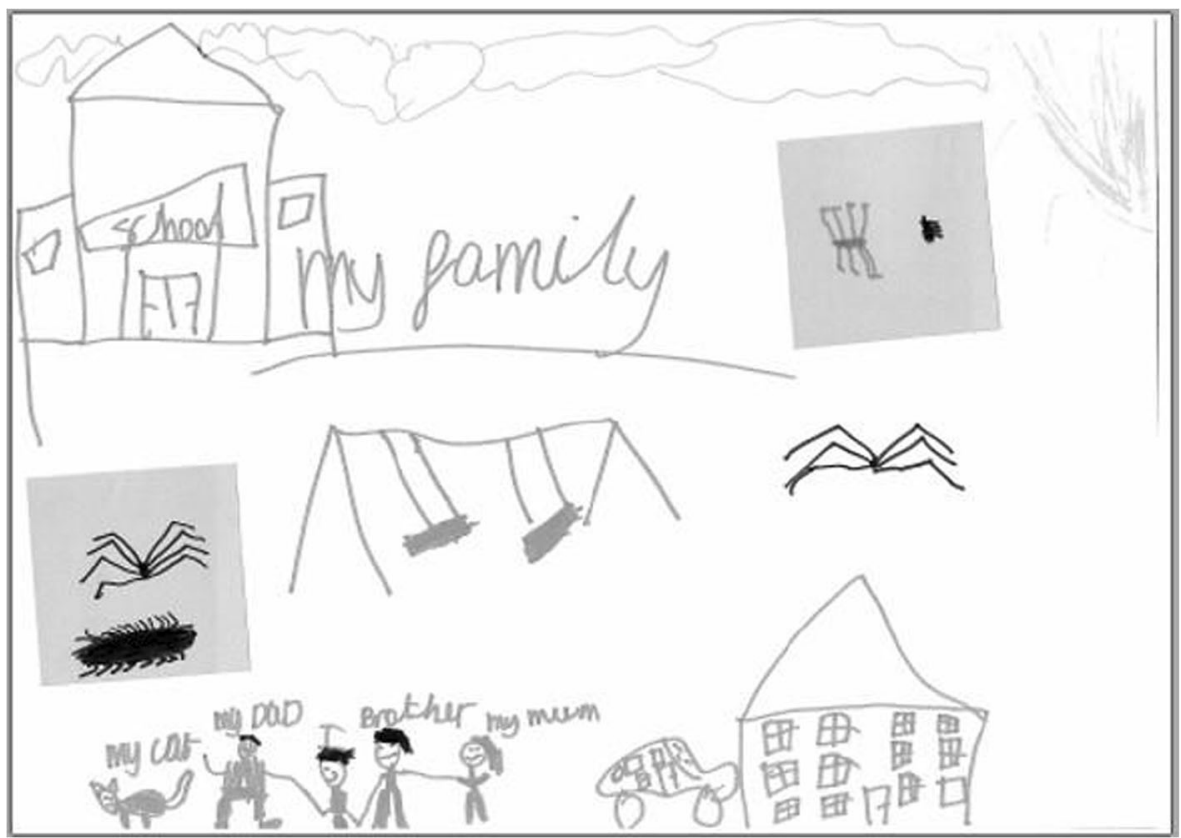

Image 1: Sources of support (family, friends, pets).

The final subtheme was that children need to have a positive self-image. Altruism and kindness appeared to be the most important aspects of this theme $(n=27)$, as

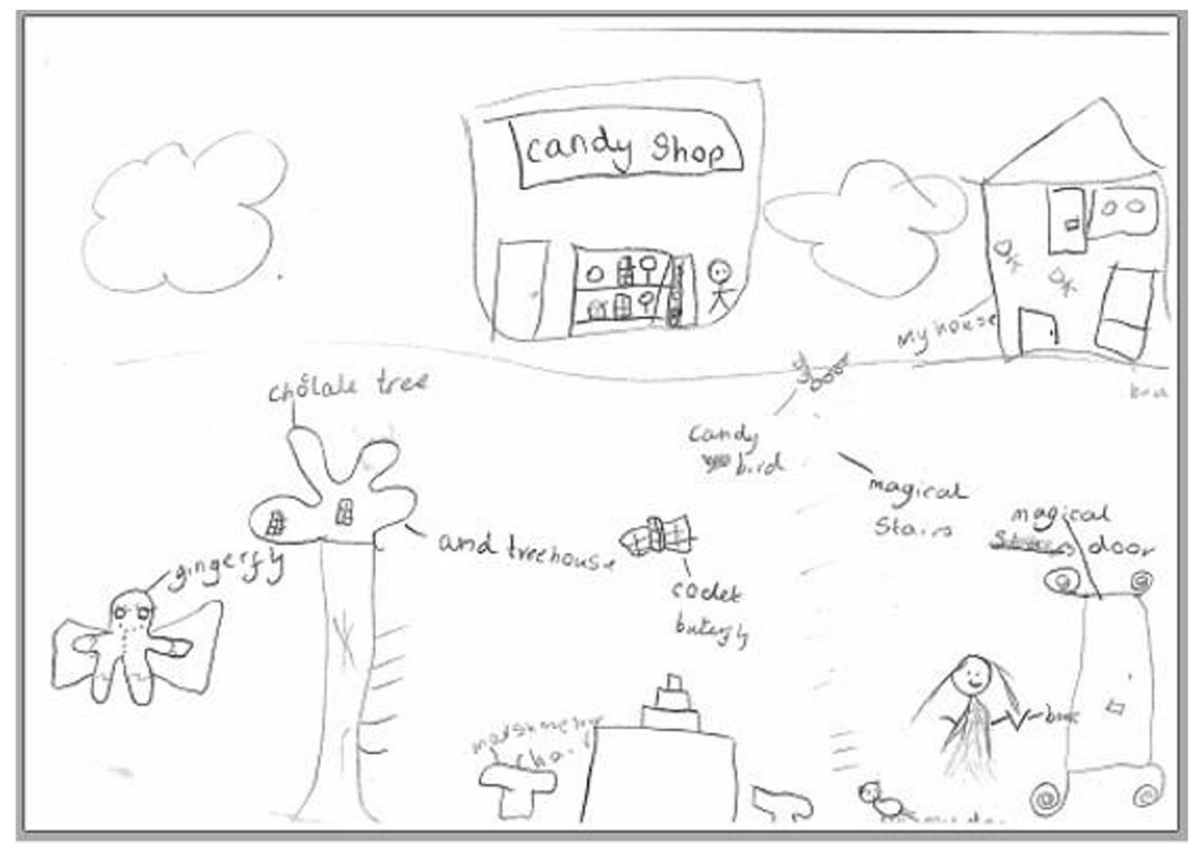

Image 2 Favourite imaginative spaces 
children said "welcome people into your home", "care for the people in need", "don't let others be lonely" and ultimately, "help others with their own wellbeing". Children also felt that it was important to be able to feel independent $(n=9)$ and confident with themselves $(n=15)$. A number of children stressed the need of having social and moral responsibilities $(n=13)$, behave to others with fairness $(n=9)$, respect $(n=6)$, and therefore being perceived as a trustworthy person $(n=6)$. As children said, "We need responsibility; if your mum trusts you she will give you responsibility", "we need to contribute to our family", and "we need people that we can trust and they can trust $u$ ". Self-regulation was also linked to how children perceived themselves $(n=13)$, particularly being in control of the emotions, but also being able to experience all kinds of emotions; "We need all feelings; happiness, sadness, anger, excitement, all of them", "the world would be all grey without all kinds of feelings". Lastly, a few children mentioned the importance of being calm $(n=7)$ and positive $(n=6)$; "We need kisses, hugs and cuddles that help us to be calm", "to take big breaths and meditate", and "to have every joyfulness inside the body".

\subsection{Physical wellbeing}

The second theme presents the aspects of wellbeing that are related to children's physical health and wellbeing. For example, most children referred to the importance of having a balanced diet (including sweets and snacks occasionally) $(n=12)$ in order 'to have a good brain, bones, eyes, lungs; a good body'. Having good quality of sleep was also important $(n=5)$, following by good hygiene $(n=4)$ (i.e. hand washing, showers). Lastly, two children referred to their need of having access to medical care and medicine when they need to, and that this care should be free for all; "you need to be able to take your medicine for free when you feel poorly'. These findings reflect Children's society's report on 'Good Childhood' (, 2012) which urges the government and policy-makers to take action on children's accessibility to medical care; an action that might be more important than ever following the Covid-19 pandemic.

\subsection{Material wellbeing}

The third theme refers to children's needs for sufficient financial resources, which can further contribute to their material wellbeing. Housing appeared to be the priority in this theme $(n=52)$; specifically, we assigned the category safety to all drawings of houses that were secure and private, or when children wrote the word 'safety' on their drawings $(n=31)$. Several children extended this and drew their happy place with clear boundaries and strong walls, such as castles (Image 3); this was regarded as another indicator of children's desire for safety and security. One child also mentioned the need to 'be able to pay for your gas and electricity' as another important aspect of material wellbeing, so having financial security. We further assigned the category good quality of housing to all drawings with a clear emphasis on the appearance of houses, houses that were colourful or had nice designs, such as swimming pools and swings $(n=15)$ (Image 4). Possessions were the second most important aspect of material wellbeing $(n=38)$, such as clothing, games, toys, or bicycles. Six children also stressed their desire to have financial security and not have to worry about money; 'to not need money and be able to live for free'. These findings on material wellbeing have also 


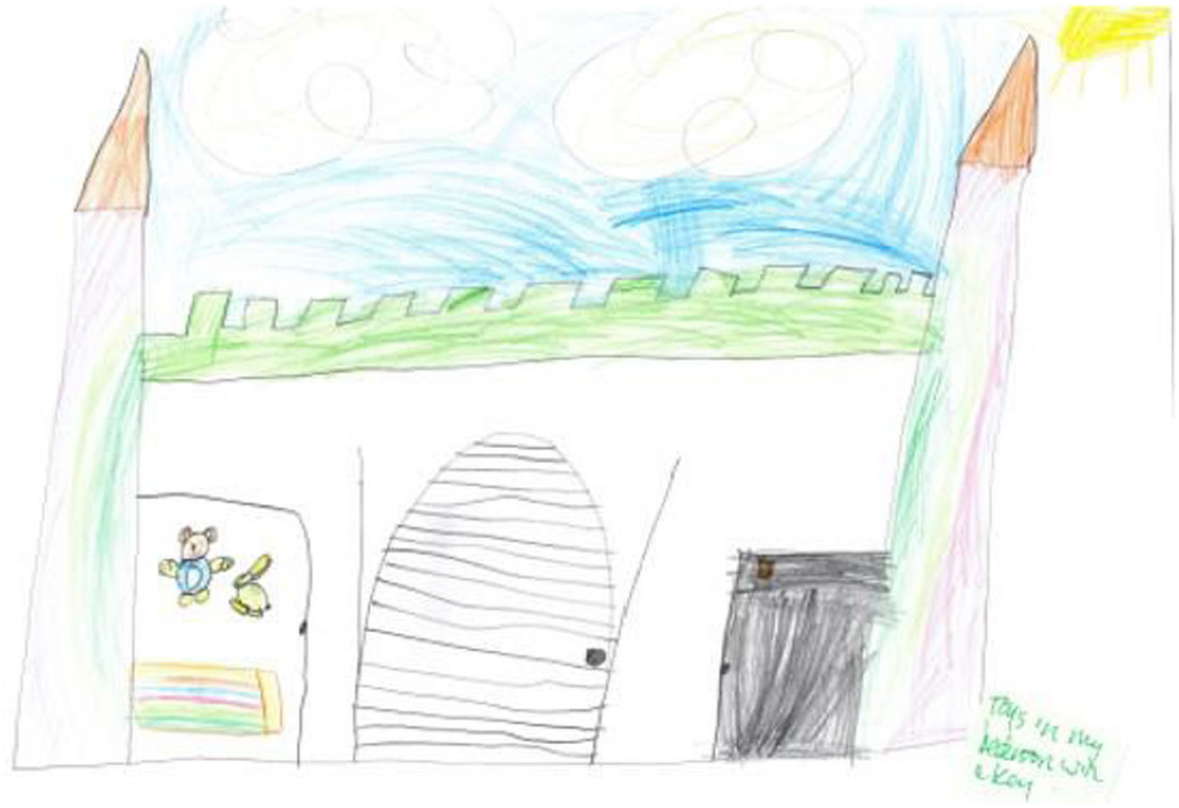

Image 3 Security of a happy space

been identified as important indicators of wellbeing in two previous studies (Andresen \& Fegter, 2011; Children's society, 2012).

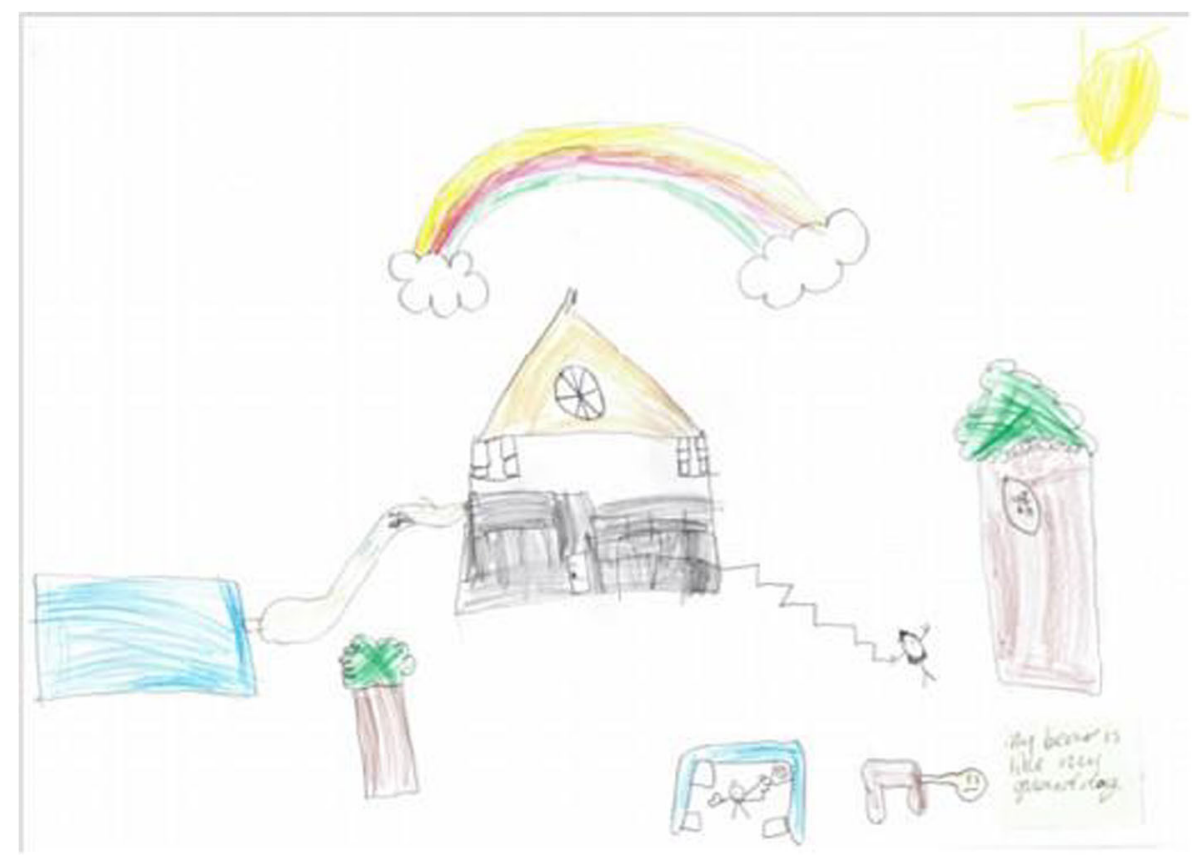

Image 4 Good quality of housing 


\subsection{Nature and outdoor spaces}

Approximately half of the children created a drawing with figures of nature and outdoor spaces, such as trees, grass, parks, gardens, lakes, rivers, outdoor playgrounds, rainbows or the sunlight $(n=56)$ (Image 5). Only 17 out of these 56 children elaborated verbally or in written text that access to nature and outdoor spaces gives them opportunities for enjoyment, creativity, and physical activity; 'we can be adventurous', 'we can create things'. Access to such spaces also appeared to allow children to relax and 'be calm and peaceful'. Children discussed fondly about relaxing in spaces where they can 'see and smell the blossoms and the flowers', 'look at the blue sky' or 'see the rivers that make nice sounds'. Trees appeared to have a special meaning, as one in three children drew a tree around their favourite and happy place. As they mentioned: 'trees give us oxygen', 'trees give us shelter', 'when it rains we go under the trees', 'we need 20 million trees!'. They also expressed a sense of responsibility towards the nature, as they said that 'we need to plant and feed more trees, plants and flowers' in order to 'protect our environment'.

Interestingly, these representations of nature predominantly exist in the background of the drawings, and were rarely the main focus of either the drawings or children's verbal and written expressions. As such, while children in this study tended to include elements of nature within their happy places, they were generally not foregrounded as a central component of that place, nor were they mentioned explicitly when discussing what is important for their wellbeing. This has led us as researchers to consider the possibility that being naturally connected is often an implicit sense; one that is, therefore, not usually articulated. This might explain why the children who participated in previous psychological studies of wellbeing did not explicitly mention it when they were asked to write or talk about what makes them happy. Moreover, it could be that children are taking for granted the presence of nature within their happy places. It is also possible that the method of drawing elicits elements of wellbeing that are deeper seated and the discussions that arise during the drawing process 'draw' these more subconscious elements of wellbeing out. This is potentially significant for our current study which specifically explores the impact of working with artists in nature on children's wellbeing; however, this needs further exploration.

Children's drawings depict nature and outdoor spaces as being interconnected with all aspects of wellbeing; for this reason, we have included this as an overarching theme in Fig. 1. For example, having the opportunity to play and be adventurous outside can contribute to physical health and wellbeing, whilst being able to stay calm and appreciate the beauty of the nature can be linked to emotional and mental wellbeing. At the same time, access to these spaces might also be linked to financial resources and, therefore, the material wellbeing; this is because wealth often determines access to nature (Lee \& Maheswaran, 2010) with children living in areas of high deprivation being less likely to have access to green spaces or to participate in outdoor recreation activities (Marmot, 2013).

\subsection{Opportunities for learning, growth and leisure}

Having opportunities to participate in activities, go on trips or holidays $(n=18)$, were also difficult to separate from other aspects of wellbeing within children's drawings. 

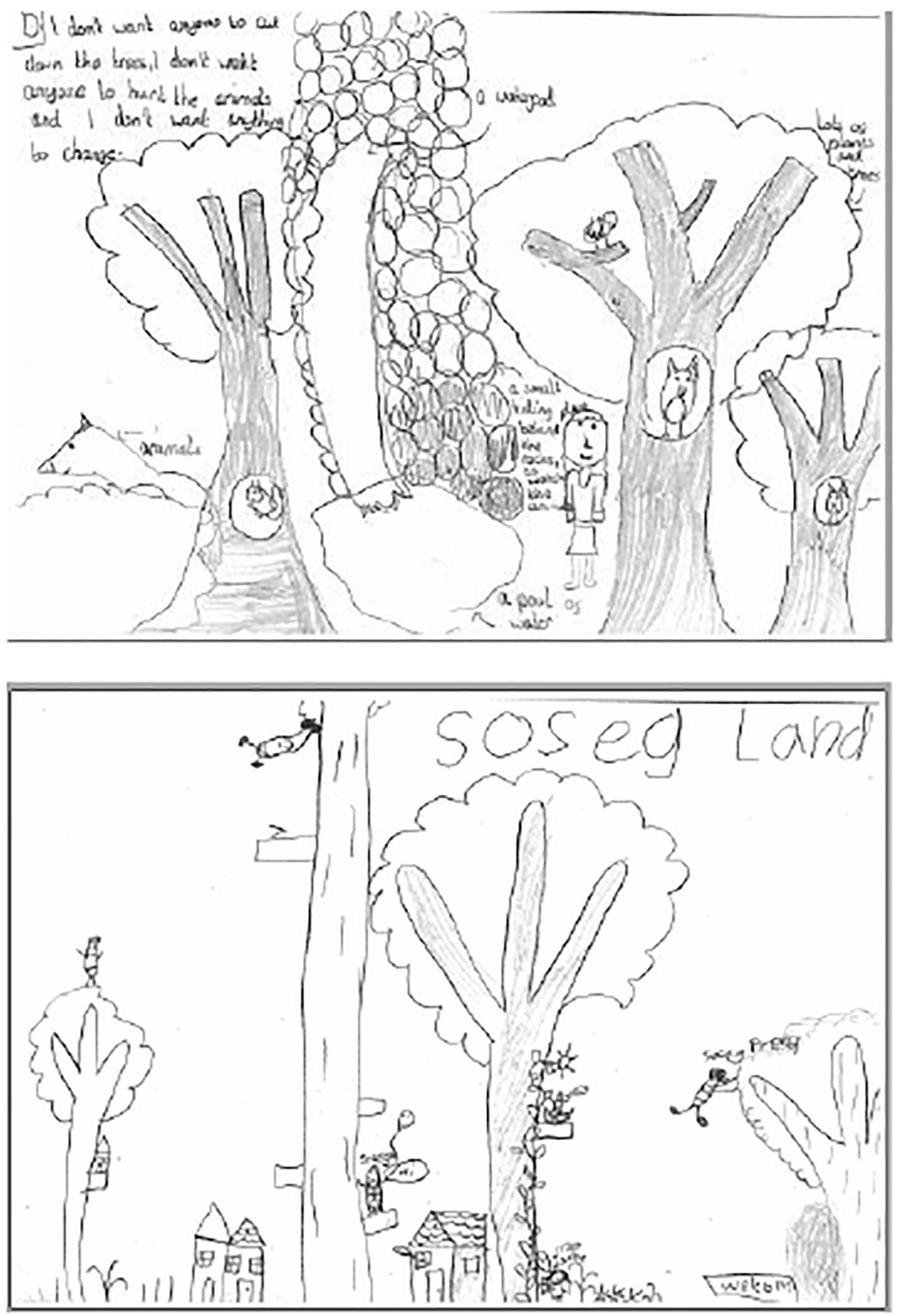

Image 5 Nature and outdoor spaces

For example, being able to join a sports club can contribute to physical wellbeing through active physical exercise, while being part of a group and doing something enjoyable can enhance both mental and emotional wellbeing. At the same time, 


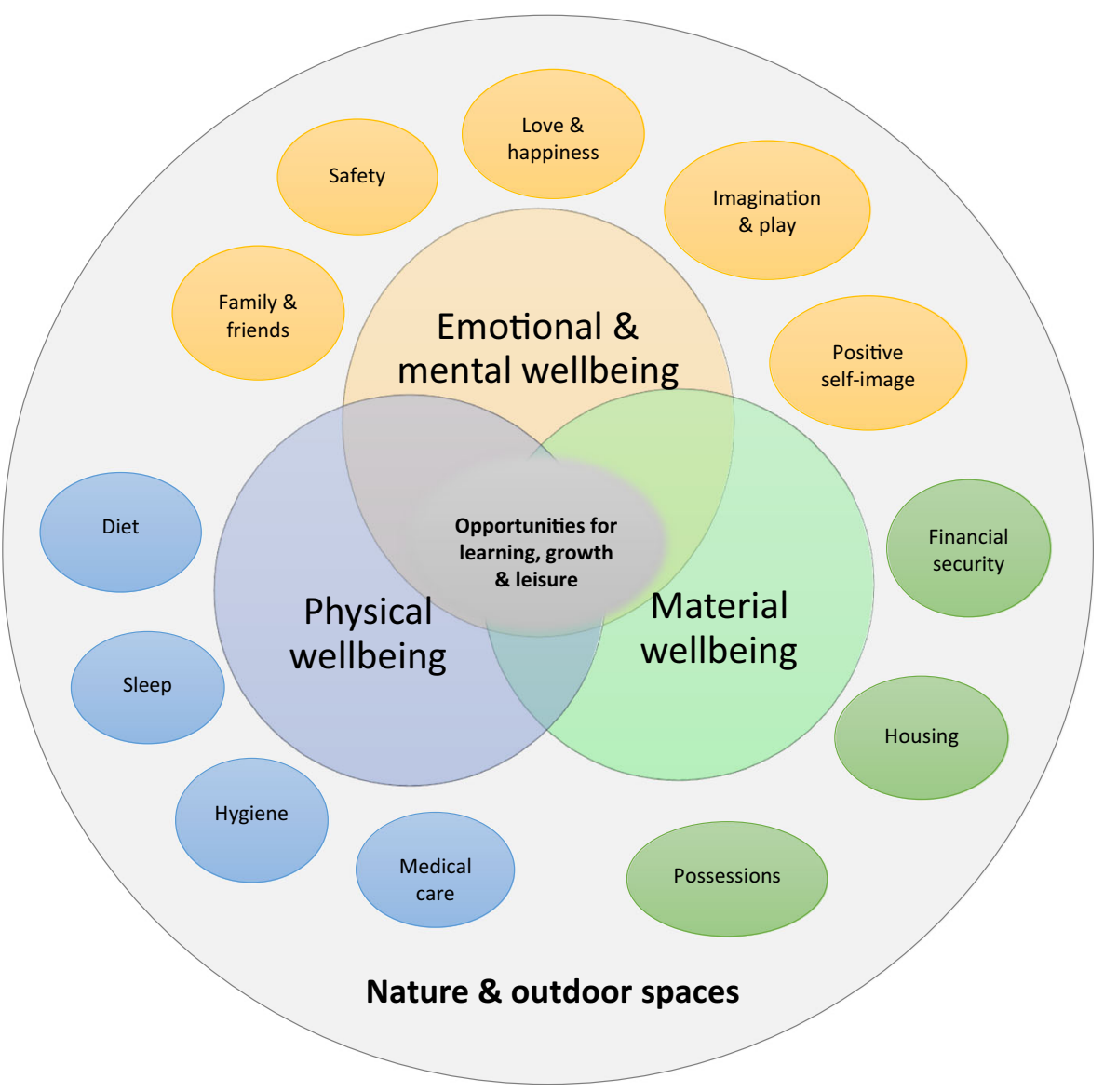

Fig. 1 Children's wellbeing themes

financial resources are essential in order to be able to afford such activities. For this reason, it is located in the centre of the three central overlapping themes within Fig. 1. The activities that children mentioned most frequently tended to be related to their favourite sports and hobbies (i.e. cycling, boxing, football), being involved with the arts (i.e. drawing, playing music, singing, dancing), or watching live events (Image 6). These findings echo the results from previous studies, which identified the opportunities for learning and play as crucial indicators of children's wellbeing (Andresen \& Fegter, 2011; Children's society, 2012).

\subsection{Things to Keep Away}

Children were also invited to draw the things that they would want to keep away from their happy places. In response, they mainly referred to violence, fighting, shouting, rudeness, cheating, and killing (not only people, but also animals and trees). They also expressed their desire to keep away 'people who look scary', bad spirits, bad weather, bad luck, and bad mood. Perhaps due to the timing of this study (one week before the lockdown was imposed as a result of Covid-19), fourteen children highlighted that they 

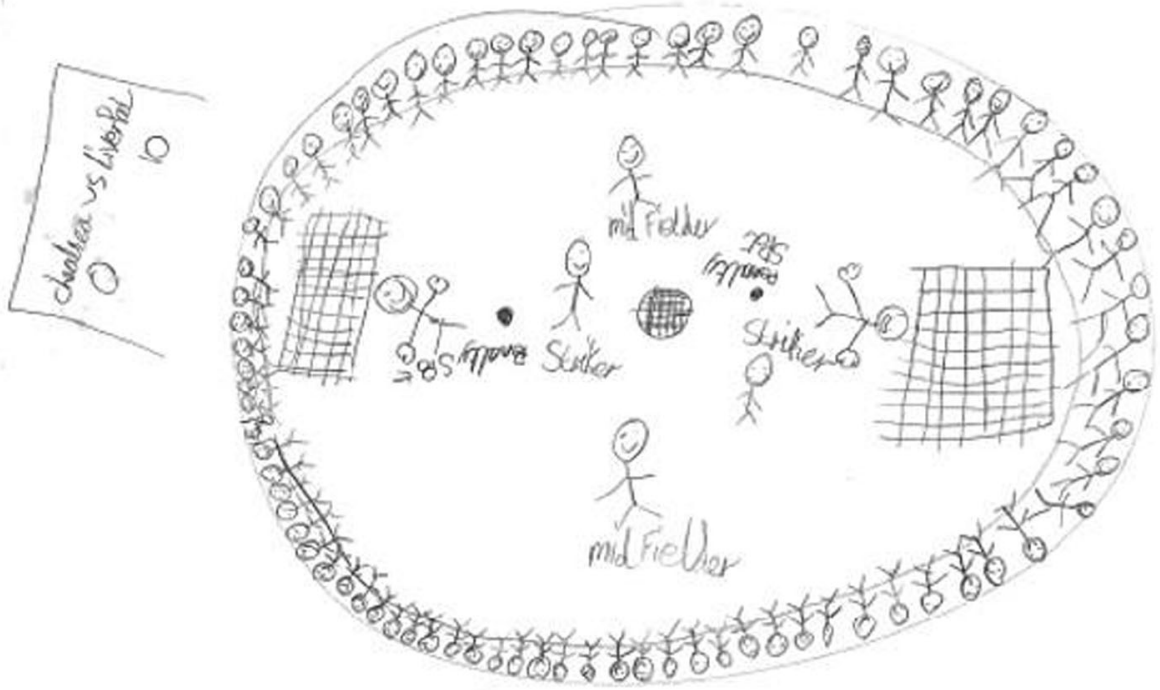

Image 6 Affordability for activities

wish to stay away from illness, specifically the coronavirus, and also loneliness which would be an inevitable outcome of the lockdown for most children. Loneliness might not necessarily be linked to the Covid-19 outbreak, but it is possible that children were aware of the implications by watching the news from parts of the world where the outbreak started earlier. Also, one child wrote on the drawing that 'I don't want anything to change', suggesting that change as they were potentially anticipating from the pandemic conditions, or the fear of change, might also negatively affect children's wellbeing.

\section{Discussion}

As detailed above, more than half of the children who participated in this study (56 out of 91) included a representation of nature or outdoor space within their drawing; the theme that received the most attention. While the majority of these did not foreground nature, 17 out of 56 children (or approximately one in five) focused explicitly on the importance of the environment and nature for their wellbeing (e.g. Image 5). This appears to be a significant observation considering that, in previous studies, when children were asked about what constitutes their own wellbeing, nature was rarely mentioned (i.e. Andresen \& Fegter, 2011; Coverdale \& Long, 2015; Fane et al., 2020; Fattore et al., 2009). As detailed in the literature review, previous studies have demonstrated how human-nature connectedness has a restorative effect for children's wellbeing (Milligan \& Bingley, 2007; Rudkowski, 2014; Walshe et al., 2020b; Walshe et al., 2020a); within this study a small percentage of children at least appear to recognise this. For the remaining 39 children for whom nature is not foregrounded in their drawings but is present in some form or other, there is a concern that if the 
connections between nature and wellbeing remain only implicit, it may be less likely that they will get involved in conscious efforts to protect and sustain the environment (Milstein, 2011). While further research is needed to explore this analysis, it nevertheless seems important to develop interventions and services that can restore this humannature connectedness and make the benefits for wellbeing apparent.

In the few cases where children made nature explicit in their drawings, it was clear that access to green and outdoor spaces offered them opportunities for relaxation, creativity, and play - essentially opportunities for happiness. The appreciation of the beauty of nature that can be found, for example in trees and flowers, also appeared to have a strong impact on children's sense of happiness and life satisfaction. These illustrations, therefore, allowed us to make connections with one of the key theories to human-nature relationship, Ulrich's psychoevolutionary theory (Ulrich, 1993). Ulrich's theory posits humans' innate affiliation with natural environments (Richardson \& McEwan, 2019), drawing upon the assumption that natural environments induce positive emotions and feelings. This human-nature connectedness can help people to view themselves as part of a wider ecology which has a positive impact on aspects of wellbeing, such as vitality, creativity and happiness (Capaldi et al., 2014). This, in turn, allows us to create further links with positive psychology, such as the PERMA theory (Seligman \& Csikszentmihalyi, 2000) which argues that the positive states and traits that children can cultivate while in nature (i.e. gratitude, joy, inspiration) are a big contributor to wellbeing. Seligman and Csikszentmihalyi (2000) suggest that the more we cultivate this state of mind, the happier we can be; it is, therefore, important that children are offered opportunities from the early stages of life.

Another important component of positive psychology theory is relatedness. In fact, almost half of the children referred to the importance of relatedness and belonging with family, friends and the community, as a crucial aspect of their wellbeing. Seligman and Csikszentmihalyi (2000) ague that positive relationships and engagement with others can lead to positive emotions and an enhanced sense of meaning in life - and vice versa. Relatedness and belonging are also a key element of the self-actualisation theory (Deci \& Ryan, 2008), which argues that wellbeing is based upon the fulfilment of three core needs: agency, mastery and relatedness. Evidence suggests that when children are able to relate to others and develop healthy relationships, they feel more confident in their ability to fulfil their own potential (what is known as self-actualisation) (Ryan \& Deci, 2000). Through this sense of belonging and relatedness, children can progress towards the development of autonomy, agency and mastery over their own life (Deci \& Ryan, 2008); all of which are enablers of children's wellbeing. This is another important finding for future research and practice which indicates the need to help children connect with others and cultivate healthy relationships.

Taking this argument further, environmental psychologists have long suggested that this sense of relatedness with other people can be enhanced by connectedness and relatedness with nature (Nielsen \& Hansen 2007; Townsend \& Weerasuriya, 2010). Burls (2007) showed how models that promote ecological health have informed the development of strategies such as "healthy schools" which demonstrate how natural environments encourage healthy relationships in childhood. Based on humanistic theoretical principles, Burls (2007) suggested that growing affection and emotional attachment to nature affects positively the connection, fondness and trust between 
people. In addition, previous studies have shown that green spaces can be suitable for the development of relationships with cross ethnic and cultural boundaries, within a restorative and aesthetically pleasing environment (Dyment \& Bell, 2006; Seeland et al., 2009). With this in mind, the benefits of relatedness with nature can be transposed onto the relatedness with other people, and vice versa. The notion of 'caring for oneself, each other and the earth' (Ärlemalm-Hagsér \& Engdahl, 2015) is the most relevant here as it clearly highlights the interconnectedness between relatedness and environmental sustainability.

One perhaps surprising observation emerging from the data was that children expressed their need not only to receive love and happiness from others, but it was equally important for them to be able to give it back to other people. For example, they wrote on their drawings 'to give love and happiness', 'to show respect and fairness'. Several children also highlighted their need to have social and moral responsibilities, such as helping and caring for others, and being able to contribute to the society. This need for care-giving suggests links with the social mentality theory (Hermanto \& Zuroff, 2016), according to which self-compassion and self-reassurance are ways of relating to oneself with care and kindness when difficult life struggles occur (Gilbert et al., 2004). Engaging in the process has been associated with a brain region (left insula activation) that is linked to compassion, empathy and care toward others (Lutz et al., 2008). This suggests that caring for the self and caring for others may be neurologically linked. Existing research shows that care-giving and care-seeking have profound effects on positive psychological functioning, greater purpose in life and life satisfaction (Neely et al., 2009). In this study, children as young as seven years old already appeared to be aware of how caring for others and contributing to the society has a profound impact on their own wellbeing; in current times perhaps this sense of care can be extended to the natural environment.

Some aspects of the findings from this study appeared to differ from those of previous studies on children's perceptions of wellbeing. These differences may have arisen predominantly from the lens of the methodological analysis we followed, which was largely based on children's visual illustrations. This methodological approach allowed us to uncover aspects of wellbeing that might be only subconsciously recognised, such as the impact of the environment and nature. The development of interventions which directly target the human-nature connectedness may help to gain awareness of these rather 'quiet' aspects of wellbeing, and to contribute to the longterm collective efforts on sustainable living. Particularly children's need for relatedness, care-taking and care-giving as discussed above, may be aligned with the notion of 'caring for oneself, others and the environment'; a key aspect of sustainability (Ärlemalm-Hagsér \& Engdahl, 2015). The Sustainable Development Solutions Network (2014) has emphasized that working with young children provides a window of opportunity to lay strong foundations for long-term knowledge, skills and attitudes which can play a substantial role on societal improvements. Engaging young children has been also recognised as a key element in promoting a lifelong disposition towards caring for the others and the environment (Barratt Hacking et al., 2007). It is, therefore, crucial to utilise this opportunity and work with children towards setting long-term targets that will impact the wellbeing of both the current and future generations.

It is important to highlight that, although these findings stem purely from children's drawings and discussions, our own personal bias as researchers might have affected the 
interpretation of the results. The involvement of three researchers who investigated the results individually aimed to minimise the influence of individual viewpoints, and it is important to note that as researchers we come from distinct conceptual frameworks ourselves including geography, natural science and psychology. It is also important to note that the findings are limited to the perspectives of children from four classes and two schools within similar geographical locations. Considering the highly contextualised nature of childhood, children within different contexts may perceive their own wellbeing differently. Therefore, the findings need to be considered in combination with previous studies in the field, as they were summarised in the literature review.

\section{Conclusion}

The findings of this study showed that there are a range of aspects of wellbeing that are explicit in children's drawings, for example a sense of safety, positive relationships with family and friends, as well as the need for love and happiness were among the most explicit aspects of wellbeing in children's drawings. However, other elements are less well represented. In particular, the importance of nature, while commonly referenced, predominantly remained in the background of drawings. Interestingly, this is also an aspect that is often missing from the literature on children's wellbeing, despite being a major topic of interest in both mainstream and academic literature across the past two decades (e.g. Mitchell \& Popham, 2008; Jordan and Chawla (2019). We have speculated that this implicit nature of references in children's drawings could be because of a general tendency towards taking for granted the presence of nature for positive wellbeing. This might explain why being naturally connected might not be as explicitly or clearly articulated as other indicators of wellbeing, such as the desire for positive relationships, safety, love and happiness.

This study may be a starting point for bringing together the burgeoning literature of children's wellbeing indicators from a psychological and environmental point of view. We suggest that the child-focused insights that we explored should be taken into consideration for the effective tailoring of future interventions and services that aim to support children's wellbeing. We also recommend that future research in this field consider the findings that come from less traditional methods of understanding children's perspectives, such as drawing, and to incorporate these in future frameworks and indicators of wellbeing. Future research may further need to focus on understanding child-identified indicators of wellbeing especially during pivotal times (Fattore et al., 2019), such as the Covid-19 pandemic. The inclusion of children's voice at this stage is necessary to ensure that the development of any urgent educational and public health practices and policies are sensitive to children's needs and lived experiences.

Taking this knowledge forward, our next steps are to foreground the essence of nature and sustainability through engaging children with arts in nature through the Ecocapabilities research project. We hope that we will be able to explore potential changes in children's perceptions of wellbeing following continuous exposure to nature and outdoor spaces alongside their classmates, teachers, artists and researchers. We also hope that this child-centred knowledge will shape the foundation and space where arts and nature meet, providing a safe space for a healthy childhood. 


\section{References}

Amerijckx, G., \& Humblet, P. C. (2013). Child well-being: What does it mean? Children \& Society, 28(5), 404 415. https://doi.org/10.1111/chso. 12003.

Andresen, S., Bradshaw, J., \& Kosher, H. (2019). Young children's perceptions of their lives and well-being. Child Indicators Research, 12(1), 1-7. https://doi.org/10.1007/s12187-018-9551-6.

Andresen, S., \& Fegter, S. (2011). Children growing up in poverty and their ideas on what constitutes a good life: Childhood studies in Germany. Child Indicators Research, 4, 1-19. https://doi.org/10.1007/s12187010-9073-3.

Andresen, S., Fegter, S., Hurrelmann, K., \& Schneekloth, U. E. (2017). Well-being, poverty and justice from a Child's perspective: In 3rd world vision children study. Dordrecht: Springer Publications

Ärlemalm-Hagsér, E., \& Engdahl, I. (2015). Caring for oneself, others and the environment: Education for sustainability in Swedish preschools. Young Children and the Environment, 251-263. https://doi. org/10.1017/cbo9781107280236.016.

Barratt Hacking, E., Barratt, R., \& Scott, W. (2007). Engaging children: Research issues around participation and environmental learning. Environmental Education Research, 13(4), 529-544. https://doi.org/10.1080 $/ 13504620701600271$.

Barnes, S. (2006). Space, choice and control, and quality of life in care settings for older people. Environment and Behavior, 38(5), 589-604. https://doi.org/10.1177/0013916505281578.

Ben-Arieh, A., \& Kosher, H. (2018). The child study movement: Encyclopedia of child and adolescent development. Wiley publication.

Boyd, F., White, M. P., Bell, S. L., \& Burt, J. (2018). Who doesn't visit natural environments for recreation and why: A population representative analysis of spatial, individual and temporal factors among adults in England. Landscape and Urban Planning, 175, 102-113. https://doi.org/10.1016/j. landurbplan.2018.03.016.

Burls, A. (2007). People and green spaces: Promoting public health and mental wellbeing through ecotherapy. Journal of Public Mental Health, 6(3), 24-39.

Braun, V., \& Clarke, V. (2008). Using thematic analysis in psychology. Qualitative Research in Psychology, 3(2), 77-101. https://doi.org/10.1191/1478088706qp063oa.

British Educational Research Association [BERA]. (2018). Ethical guidelines for educational research (4th ed.). London: https://www.bera.ac.uk/researchers-resources/publications/ethicalguidelines-foreducational-research-2018.

Brymer, E., Freeman, E., \& Richardson, M. (2019). One health: The wellbeing impacts of human-nature relationships. Frontiers in Psychology, 10. https://doi.org/10.3389/fpsyg.2019.01611.

Capaldi, C. A., Dopko, R. L., \& Zelenski, J. M. (2014). The relationship between nature connectedness and happiness: A meta-analysis. Frontiers in Psychology, 5. https://doi.org/10.3389/fpsyg.2014.00976

Cervinka, R., Röderer, K., \& Hefler, E. (2011). Are nature lovers happy? On various indicators of well-being and connectedness with nature. Journal of Health Psychology, 17(3), 379-388. https://doi.org/10.1177 $/ 1359105311416873$.

Clift, S., \& Stickley, T. (2017). Arts, health and wellbeing: A theoretical enquiry for practice. Cambridge: Cambridge Scholars Publishing.

Cochran, P. A., Marshall, C. A., Garcia-Downing, C., Kendall, E., Cook, D., McCubbin, L., \& Gover, R. M. (2008). Indigenous ways of knowing:Implications for participatory research and community. American Journal of Public Health, 98(1), 22-27. https://oi.org/10.2105/AJPH.2006.093641.

Culshaw, S. (2019). The unspoken power of collage? Using an innovative arts-based research method to explore the experience of struggling as a teacher. London Review of Education, 17(3), 268-283. https://doi.org/10.18546/lre.17.3.03.

Daykin, N. (2019). Arts, health and well-being: A critical perspective on research, policy and practice. London: Routledge.

Deci, E. L., \& Ryan, R. M. (2008). Self-determination theory: A macrotheory of human motivation, development, and health. Canadian Psychology, 49(3), 182-185. https://doi.org/10.1037/a0012801.

Denzin, N. K., \& Lincoln, Y. S. (2005). The SAGE handbook of qualitative research (6th ed.). Thousand Oaks: Sage Publications.

Devlin, N. J., \& Appleby, J. (2010). Getting the most out of RPOMs: Putting health outcomes at the heart of NHS decision-making. Office of Health Economics: The Kings Fund.

Diener, E., \& Seligman, M. E. P. (2004). Beyond money: Toward an economy of well-being. Psychological Science in the Public Interest, 5(1), 1-31. https://doi.org/10.1111/j.0963-7214.2004.00501001.x. 
Dyment, J. E., \& Bell, A. C. (2006). Our garden is colour blind, inclusive and warm: Reflections on green school grounds and social inclusion. International Journal of Inclusive Education, 12(2), 169-183.

Children's Society (2012). Promoting positive well-being for children: A report for decision-makers in parliament, central government and local areas. The Children's Society. https://www.childrenssociety. org.uk/what-we-do/resources-and-publications/publications-library/promoting-positive-well-beingchildren-re .

Coverdale, G. E., \& Long, A. F. (2015). Emotional wellbeing and mental health: An exploration into health promotion in young people and families. Perspectives in Public Health, 135(1), 27-36. https://doi. org/10.1177/1757913914558080.

Edwards, B., \& Bromfield, L. M. (2009). Neighborhood influences on young children's conduct problems and pro-social behavior: Evidence from an Australian national sample. Children and Youth Services Review, 31, 317-324. https://doi.org/10.1016/j.childyouth.2008.08.005.

Fancourt, D., \& Finn, S. (2019). What is the evidence on the role of the arts in improving health and wellbeing? A scoping review. Health evidence network synthesis report (no. 67). Copenhagen: WHO regional Office for Europe. https://www.ncbi.nlm.nih.gov/books/NBK553773/.

Fane, J., MacDougall, C., Jovanovic, J., Redmond, G., \& Gibbs, L. (2020). Preschool aged children's accounts of their own wellbeing: Are current wellbeing indicators applicable to young children? Child Indicators Research, 13, 1893-1920. https://doi.org/10.1007/s12187-020-09735-7.

Fattore, T., Fegter, S., \& Hunner-Kreisel, C. (2019). Children's understandings of well-being in global and local contexts: Theoretical and methodological considerations for a multinational qualitative study. Child Indicators Research, 12, 385-407. https://doi.org/10.1007/s12187-018-9594-8.

Fattore, T., Mason, J., \& Watson, E. (2009). When children are asked about their well-being: Towards a framework for guiding policy. Child Indicators Research, 2, 57-77. https://doi.org/10.1007/s12187-0089025-3.

Fattore, T., Mason, J., \& Watson, E. (2017). Children's understandings of well-being. children's well-being: Indicators and research. Dordrecht: Springer Netherlands.

Forgeard, M. J. C., Jayawickreme, E., Kern, M. L., \& Seligman, M. E. P. (2011). Doing the right thing: Measuring wellbeing for public policy. International Journal of Wellbeing, 1(1). https://doi.org/10.5502 /ijw.v1i1.15.

Frosh, S. (2002). Key concepts in psychoanalysis. New York: New York University Press.

Gilbert, P., Clarke, M., Hempel, S., Miles, J. N. V., \& Irons, C. (2004). Criticizing and reassuring oneself: An exploration of forms, styles and reasons in female students. British Journal of Clinical Psychology, 43(1), 31-50. https://doi.org/10.1348/014466504772812959.

Gillett-Swan, J. K., \& Sargeant, J. (2014). Wellbeing as a process of accrual: Beyond subjectivity and beyond the moment. Social Indicators Research, 121(1), 135-148. https://doi.org/10.1007/s11205-014-0634-6.

Hermanto, N., \& Zuroff, D. C. (2016). The social mentality theory of self-compassion and self-reassurance: The interactive effect of care-seeking and caregiving. The Journal of Social Psychology, 156(5), 523-535. https://doi.org/10.1080/00224545.2015.1135779.

Jones, P. (2005). The arts therapies: A revolution in healthcare. New York: Routledge Publications

Jordan, C., \& Chawla, L. (2019). A coordinated research agenda for nature-based learning. Frontiers in Psychology, 10, 766. https://doi.org/10.3389/fpsyg.2019.00766.

Kamerman, S. B., Neuman, M., Waldfogel, J., \& Brooks-Gunn, J. (2003). Social policies, family types and child outcomes in selected OECD countries. OECD social, employment and migration working papers (no. 6). Paris: OECD publishing. https://doi.org/10.1787/625063031050.

Kaushanskaya, M., Park, J. S., Gangopadhyay, I., Davidson, M. M., \& Weismer, S. E. (2017). The relationship between executive functions and language abilities in children: A latent variables approach. Journal of Speech, Language, and Hearing Research, 60(4), 912-923. https://doi.org/10.1044/2016_ jslhrl-15-0310.

Land, K. C., \& Michalos, A. C. (2018). Fifty years after the social indicators movement: Has the promise been fulfilled? Social Indicators Research, 135, 835-868. https://doi.org/10.1007/s11205-017-1571-y.

Laurens, K. R., Tzoumakis, S., Dean, K., Brinkman, S. A., Bore, M., Lenroot, R. K., et al. (2017). The 2015 middle childhood survey (MCS) of mental health and well-being at age 11 years in an Australian population cohort. British Medical Journal Open, 7(6), e016244.

Lee, A. C. K., \& Maheswaran, R. (2010). The health benefits of urban green spaces: A review of the evidence. Journal of Public Health, 33(2), 212-222. https://doi.org/10.1093/pubmed/fdq068. 
Leitch, R. (2006). Limitations of language: Developing arts-based creative narrative in stories of teachers' identities. Teachers and Teaching: Theory and Practice, 12(5), 549-569.

Lutz, A., Brefczynski-Lewis, J., Johnstone, T., \& Davidson, R. J. (2008). Regulation of the neural circuitry of emotion by compassion meditation: Effects of meditative expertise. PloS One, 3(3), e1897. https://doi. org/10.1371/journal.pone.0001897.

Maccagnan, A., Wren-Lewis, S., Brown, H., \& Taylor, T. (2019). Wellbeing and society: Towards quantification of the co-benefits of wellbeing. Social Indicators Research, 141, 217-243. https://doi. org/10.1007/s1 1205-017-1826-7.

Mannay, D., Staples, E., Hallett, S., Roberts, L., Rees, A., Evans, R., \& Andrews, D. (2017). Enabling talk and reframing messages: Working creatively with care experienced children and young people to recount and re-represent their everyday experiences. Child Care in Practice, 25(1), 51-63. https://doi.org/10.1080 /13575279.2018.1521375.

Marmot, M. (2013). Review of social determinants and the health divide in the WHO European region: Final report. Copenhagen: WHO Regional Office for Europe.

Mayer, F. S., \& Frantz, C. M. (2004). The connectedness to nature scale: A measure of individuals' feeling in community with nature. Journal of Environmental Psychology, 24(4), 503-515. https://doi.org/10.1016/j. jenvp.2004.10.001.

McNiff, S. (2009). Art-based research. London, Philadelphia: Jessica Kingsley Publishers

Medical Research Council. (2012). Good research practice: Principles and guidelines. In MRC Ethics series. UK: Medical Research Council https://www.mrc.ac.uk/publications/browse/good-research-practiceprinciples-and-guidelines/.

Milligan, C., \& Bingley, A. (2007). Restorative places or scary spaces? The impact of woodland on the mental well-being of young adults. Health \& Place, 13(4), 799-811. https://doi.org/10.1016/j. healthplace.2007.01.005.

Misra, G. (2018). Psychosocial interventions for health and well-being. New Delhi: Springer

Milstein, T. (2011). Nature dentification: The power of pointing and naming. Environmental Communication: A Journal of Nature and Culture, 5(1), 3-24. https://doi.org/10.1080/17524032.2010.535836.

Mitchell, R., \& Popham, F. (2008). Effect of exposure to natural environment on health inequalities: An observational population study. The Lancet, 372(9650), 1655-1660. https://doi.org/10.1016/s0140-6736 (08)61689-x.

Moore, T., \& Oberklaid, F. (2014). Health and child well-being. In A. Ben-Arieh, F. Casas, I. Frønes, \& J. E. Korbin (Eds.), Handbook of child well-being: Theories, methods and policies in global perspective (pp. 2259-2279). Springer Nature: Switzerland.

Moula, Z. (2020). A systematic review of the effectiveness of art therapy delivered in school-based settings to children aged 5-12 years. International Journal of Art Therapy, 25(2), 88-99. https://doi.org/10.1080 $/ 17454832.2020 .1751219$.

Moula, Z., Aithal, S., Karkou, V., \& Powell, J. (2020). A systematic review of child-focused outcomes and assessments of arts therapies delivered in primary mainstream schools. Children and Youth Services Review, 112. https://doi.org/10.1016/j.childyouth.2020.104928.

Natural England (2019). Monitor of engagement with the natural environment (MENE): The national survey on people and the natural environment - children and young people report. Natural England; HM Government. https://www.gov.uk/government/collections/monitor-of-engagement-with-the-naturalenvironment-survey-purpose-and-results.

Neely, M. E., Schallert, D. L., Mohammed, S. S., Roberts, R. M., \& Chen, Y.-J. (2009). Self-kindness when facing stress: The role of selfcompassion, goal regulation, and support in college students' well-being. Motivation and Emotion, 33(1), 88-97. https://doi.org/10.1007/s11031-008-9119-8.

Nielsen, T. S., \& Hansen, K. B. (2007). Do green areas affect health? Results from a Danish survey on the use of green areas and health indicators. Health \& Place, 13(4), 839-850. https://doi.org/10.1016/j. healthplace.2007.02.001.

Pebley, A. R., \& Sastry, N. (2004). Neighbourhoods, poverty and children's well-being. Santa Monica, CA: RAND Corporation. https://www.rand.org/pubs/reprints/RP1122.html.

Petermans, A., \& Cain, R. (2019). Design for wellbeing: An applied approach. New York: Routledge.

Redmond, G., Skattebol, J., Saunders, P., Lietz, P., Zizzo, G., O’Grady, E., et al. (2016). Are the kids alright? Young Australians in their middle years. Final summary report of the Australian child wellbeing project. Flinders University: Australian Council for Educational Research. www.australianchildwellbeing.com.au. 
Rees, G., Andresen, S. \& Bradshaw, J. (2016). Children's views on their lives and well-being in 16 countries: A report on the Children's Worlds survey of children aged eight years old, 2013-15. York: Children's worlds project (ISCWeB). http://isciweb.org/_Uploads/dbsAttachedFiles/8yearsoldreport.pdf.

Richardson, M., \& McEwan, K. (2018). 30 days wild and the relationships between engagement with nature's beauty, nature connectedness and well-being. Frontiers in Psychology 9 https://www.frontiersin. org/articles/10.3389/fpsyg.2018.01500/full.

Richardson, M., \& McEwan, K. (2019). 30 days wild and the relationships between engagement with nature's beauty, nature connectedness and well-being. Frontiers in Psychology, 9 https://www.frontiersin. org/articles/10.3389/fpsyg.2018.01500/full.

Roberts, A., \& Woods, P. A. (2018). Principles for enhancing teachers' collaborative practice: lessons from the HertsCam Network. In D. Frost (Ed.), Empowering teachers as agents of change: Enabling a nonpositional approach to teacher leadership. Cambridge: Leadership for Learning: The Cambridge Network.

Rudkowski, M. (2014). Fostering emotional wellbeing: Personal reflections from an early childhood forest program. Children, Youth and Environments, 24(3), 80-91. https://doi.org/10.7721 /chilyoutenvi.24.3.0080.

Ryan, R. M., \& Deci, E. L. (2000). Self-determination theory and the facilitation of intrinsic motivation, social development, and well-being. American Psychologist, 55(1), 68-78. https://doi.org/10.1037/0003-066 X.55.1.68.

Seeland, K., Dübendorfer, S., \& Hansmann, R. (2009). Making friends in Zurich's urban forests and parks: The role of public green space for social inclusion of youths from different cultures. Forest Policy and Economics, 11(1), 10-17. https://doi.org/10.1016/j.forpol.2008.07.005.

Seligman, M. E., \& Csikszentmihalyi, M. (2000). Positive psychology: An introduction. American Psychologist, 55(1), 5-14. https://doi.org/10.1037//0003-066x.55.1.5.

Sen, A. (2005). Human rights and capabilities. Journal of Human Development and Capabilities, 6(2), 151166. https://doi.org/10.1080/14649880500120491.

Sofer, M., \& Ben-Arieh, A. (2014). School-aged children as sources of information about their lives. In G. Melton, A. Ben-Arieh, J. Cashmore, G. Goodman, \& N. Worley (Eds.), The SAGE handbook of child research (pp. 555-575). London: SAGE.

Steckermeier, L. C. (2018). Better safe than sorry: Does agency moderate the relevance of safety perceptions for the subjective well-being of young children? Child Indicators Research, 12, 29-48. https://doi. org/10.1007/s12187-017-9519-y.

Streuli, N., Woodhead, M., \& Camfield, L. (2009). What's the use of 'well-being' in contexts of child poverty? Approaches to research, monitoring and children's participation. International Journal of Children's Rights, 17(1), 65-109. https://doi.org/10.1163/157181808X357330.

Selwyn, J., \& Wood, M. (2015). Measuring well-being: A literature review. Bristol: The Hadley Trust.

Snell, T. L., Lam, J., Lau, W., Lee, I., Maloney, E., Mulholland, N., Wilson, L., \& Wynne, L. J. (2016). Contact with nature in childhood and adult depression. Children, Youth and Environments, 26(1), 111124. https://doi.org/10.7721/chilyoutenvi.26.1.0111.

Stiglitz, J., Sen, A., \& Fitoussi, J. P. (2009). The measurement of economic performance and social progress revisited. Paris: Commission on the Measurement of Economic Performance and Social Progress. https://www.ofce.sciences-po.fr/pdf/dtravail/WP2009-33.pdf.

Talmy, S. (2010). Qualitative interviews in applied linguistics: From research instrument to social practice. Annual Review of Applied Linguistics, 30, 128-148. https://doi.org/10.1017/s0267190510000085.

Thomas, N., Graham, A., Powell, M. A., \& Fitzgerald, R. (2016). Conceptualisations of children's wellbeing at school: The contribution of recognition theory. Childhood, 23(4), 506-520. https://doi.org/10.1177 $/ 0907568215622802$.

Townsend, M., \& Weerasuriya, R. (2010). Beyond blue to green: The benefits of contact with nature for mental health and well-being. Deakin University, AU: Beyond Blue Ltd.

Ulrich, R. S. (1993). Biophilia, biophobia, and natural landscapes. In S. R. Kellert \& E. O. Wilson (Eds.), The biophilia hypothesis. Washington DC: Island Press

Walshe, N., Lee, E., Lloyd, D., \& Sapsed, R. (2020a). STEM to STEAM as an approach to human development: The potential of arts practices for supporting wellbeing. In: P. Burnard and L. Coluccigray (Eds). Why Science and Art Creativities matter: (Re-)configuring STEAM for future-making education. Critical issues in the future of learning and teaching (Vol. 18). Leiden: Brill. Pp. 337-357. 
Walshe, N., Lee, E., \& Smith, M. J. (2020b). Supporting children's well-being with art in nature: Artist pedagogue perceptions. Journal of Education for Sustainable Development, 1(15), 98-112. https://doi. org/10.1177/0973408220930708.

Wells, N. M., \& Evans, G. W. (2003). Nearby nature: A buffer of life stress among rural children. Environment and Behavior, 35(3), 311-330. https://doi.org/10.1177/0013916503035003001.

World Health Organisation (2015). Health in 2015: From MDGs millennium development goals to SDGs sustainable development goals. Switzerland: WHO. https://apps.who.int/iris/bitstream/handle/10665 /200009/9789241565110_eng.pdf;jsessionid=9EA834CCAEDD7BF85310D3F04AD0 FFCD?sequence=1.

Publisher's Note Springer Nature remains neutral with regard to jurisdictional claims in published maps and institutional affiliations. 